\title{
Front Matter: Volume 7509
}

, "Front Matter: Volume 7509," Proc. SPIE 7509, 2009 International Conference on Optical Instruments and Technology: Optoelectronic Devices and Integration, 750901 (8 December 2009); doi: 10.1117/12.852350

SDIE Event: International Conference on Optical Instrumentation and Technology, 2009, Shanghai, China 


\title{
PROCEEDINGS OF SPIE
}

\section{International Conference on Optical Instruments and Technology \\ Optoelectronic Devices and Integration}

\author{
Xuping Zhang \\ Wojtek J. Bock \\ Xuejun Lu \\ Hai Ming \\ Editors
}

\section{9-21 October 2009 \\ Shanghai, China}

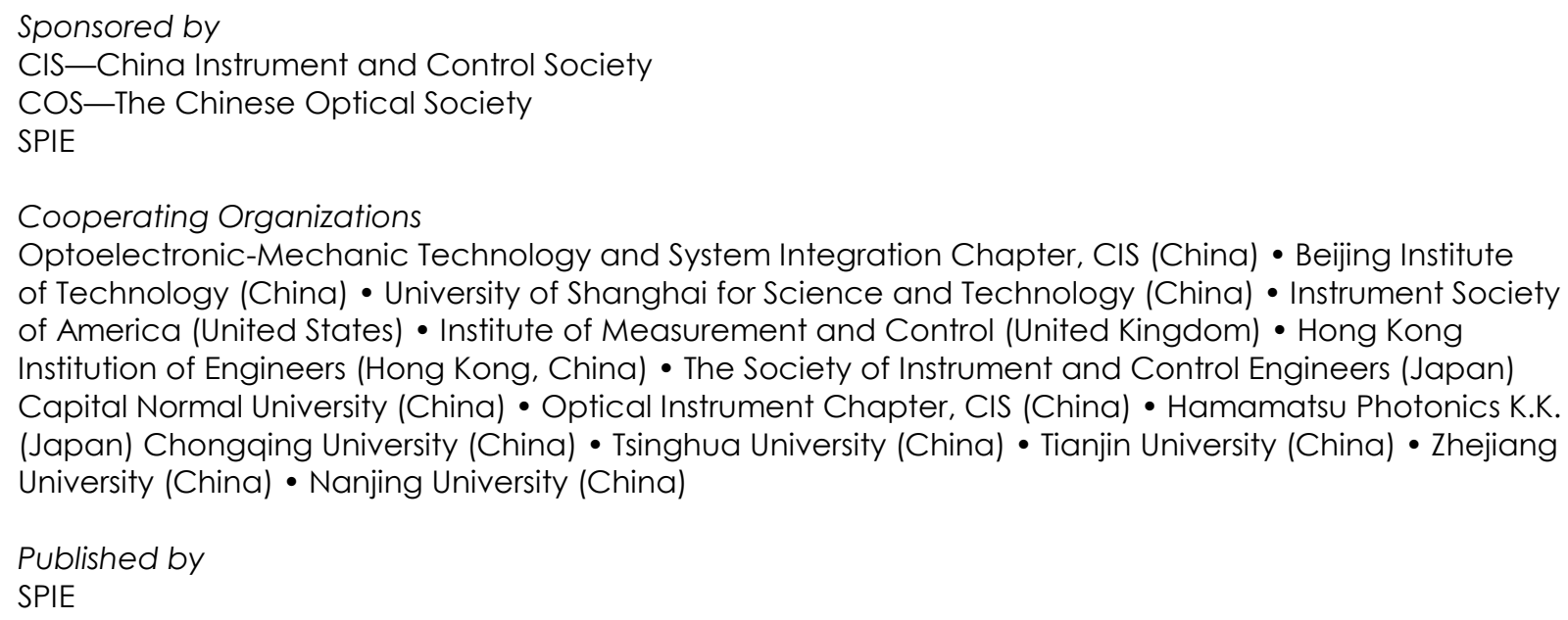


The papers included in this volume were part of the technical conference cited on the cover and title page. Papers were selected and subject to review by the editors and conference program committee. Some conference presentations may not be available for publication. The papers published in these proceedings reflect the work and thoughts of the authors and are published herein as submitted. The publisher is not responsible for the validity of the information or for any outcomes resulting from reliance thereon.

Please use the following format to cite material from this book:

Author(s), "Title of Paper," in 2009 International Conference on Optical Instruments and Technology: Optoelectronic Devices and Integration, edited by Xuping Zhang, Wojtek J. Bock, Xuejun Lu, Hai Ming, Proceedings of SPIE Vol. 7509 (SPIE, Bellingham, WA, 2009) Article CID Number.

ISSN 0277-786X

ISBN 9780819478955

Published by

SPIE

P.O. Box 10, Bellingham, Washington 98227-0010 USA

Telephone +1 3606763290 (Pacific Time) · Fax +1 3606471445

SPIE.org

Copyright (C) 2009, Society of Photo-Optical Instrumentation Engineers

Copying of material in this book for internal or personal use, or for the internal or personal use of specific clients, beyond the fair use provisions granted by the U.S. Copyright Law is authorized by SPIE subject to payment of copying fees. The Transactional Reporting Service base fee for this volume is $\$ 18.00$ per article (or portion thereof), which should be paid directly to the Copyright Clearance Center (CCC), 222 Rosewood Drive, Danvers, MA 01923. Payment may also be made electronically through CCC Online at copyright.com. Other copying for republication, resale, advertising or promotion, or any form of systematic or multiple reproduction of any material in this book is prohibited except with permission in writing from the publisher. The CCC fee code is 0277-786X/09/ $\$ 18.00$.

Printed in the United States of America.

Publication of record for individual papers is online in the SPIE Digital Library.

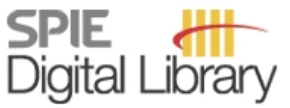

SPIEDigitalLibrary.org

Paper Numbering: Proceedings of SPIE follow an e-First publication model, with papers published first online and then in print and on CD-ROM. Papers are published as they are submitted and meet publication criteria. A unique, consistent, permanent citation identifier (CID) number is assigned to each article at the time of the first publication. Utilization of CIDs allows articles to be fully citable as soon they are published online, and connects the same identifier to all online, print, and electronic versions of the publication. SPIE uses a six-digit CID article numbering system in which:

- The first four digits correspond to the SPIE volume number.

- The last two digits indicate publication order within the volume using a Base 36 numbering system employing both numerals and letters. These two-number sets start with 00, 01, 02, 03, 04, $05,06,07,08,09,0 A, 0 B \ldots 0 Z$, followed by 10-1Z, 20-2Z, etc.

The CID number appears on each page of the manuscript. The complete citation is used on the first page, and an abbreviated version on subsequent pages. Numbers in the index correspond to the last two digits of the six-digit CID number. 


\title{
Contents
}

\author{
ix Symposium Committees \\ xi Conference Committee \\ xiii Introduction
}

SESSION 1 INTEGRATED OPTICS AND PHOTONIC INTEGRATED

750902 New encoder-decoder scheme of OCDMA with electro-optic crystal [7509-64]

G. Xu, W. Yao, R. Wang, Nanjing Univ. (China)

750903 A novel local dimming algorithm for RGB-LED backlight [7509-11]

W. Huang, Z.-L. Jin, Z.-G. Zhong, Y. Liu, Suzhou Institute of Nano-tech and Nano-bionics (China) and Suna Displays Co., Ltd. (China); D. Liu, Suna Displays Co., Ltd. (China); H. Ming, Univ. of Science and Technology of China (China); Q.-Y. Chou, F. Li, Suzhou Institute of Nano-tech and Nano-bionics (China) and Suna Displays Co., Ltd. (China)

750904 Study on far-field image using microlens array integrated with LCD [7509-44]

F. Yang, H. Chang, L. Dong, A. Wang, H. Ming, Univ. of Science and Technology of China (China)

\section{SESSION 2 PHOTONIC CRYSTAL, FIBER BRAGG GRATINGS, AND APPLICATIONS}

750905 Slanted multimode fiber gratings and applications (Invited Paper) [7509-68]

C.-L. Zhao, China Jiliang Univ. (China)

750906 Optimization for grating length of $980 \mathrm{~nm}$ single-mode semiconductor laser with dual fiber Bragg grating [7509-04]

Y. Huang, Univ. of Shanghai for Science and Technology (China); Y. Li, Univ. Of Shanghai for Science and Technology (China) and Shanghai Key Lab. of Modern Optical Systems (China); H. Wang, X. YU, H. Zhang, W. Zhang, Univ. of Shanghai for Science and Technology (China); H. Zhu, Univ. of Shanghai for Science and Technology (China) and Wuyi Univ. (China)

750907 Resonant wavelength and wavelength separation tunable dual-channel fiber Bragg grating based on filling functional material into highly birefringent photonic crystal fiber [7509-58] J. XU, Y. Liu, Z. Wang, Z. Bing, L. Yuan, B. Liu, Nankai Univ. (China)

SESSION 3 OPTICAL SWITCHERS, CONNECTORS, MODULATORS, AND OTHER ACTIVE AND PASSIVE DEVICES

$750908 \quad$ New optical instruments for coherence tomography (Invited Paper) [7509-61]

Y. Mao, S. Chang, C. Flueraru, National Research Council Canada (Canada) 
750909 Electro-optically tunable multiple channel reconfigurable OADM with Ti: $\mathrm{LiNbO}_{3}$ waveguides [7509-39]

K. Li, J. Jin, R. Zhang, X. Kong, X. Mao, Tianjin Univ. (China)

7509 OA Silicon-based digital optical switch with slot structure [7509-09]

S. Xiao, X. Wang, F. Wang, Y. Hao, X. Jiang, M. Wang, J. Yang, Zhejiang Univ. (China)

7509 OB High-speed magneto-optic switch for optical communication [7509-21]

J. Ruan, Z. Weng, S. Lin, Xiamen Univ. (China)

7509 OC Adiabatic soliton compressor based on quasi-distributed gain [7509-22]

D. Jia, Y. Wu, R. Lei, Z. Wang, Tianjin Univ. (China)

7509 OD A novel demultiplexer based on SOAs-MZI using couplers of space structure [7509-66]

K. Zhong, T. Li, N. Jia, Beijing Jiaotong Univ. (China)

7509 OE Influence of the concentration of $O$ vacancy on electronic structure and conduction properties of V-doped anatase $\mathrm{TiO}_{2}$ [7509-49]

C. Zhao, G. Liu, Q. Wan, L. Chen, Z. Xiong, Jiangxi Science and Technology Normal Univ. (China)

\section{SESSION 4 OPTICAL MEASUREMENT AND ANALYSIS}

7509 OF Blue spectral shift of P3HT organic film by KrF excimer laser ablation (Invited Paper) [7509-67] L. Jiang, Aichi Institute of Technology (Japan) and Suzhou Univ. of Science and Technology (China); X. Bao, Y. Uchida, Aichi Institute of Technology (Japan); J. Liu, Southeast Univ. (China); Y. P. Kathuria, H. Furuhashi, Y. Uchida, Aichi Institute of Technology (Japan)

7509 OG Analysis of transmission spectral characteristics of the photonic crystal fiber grating [7509-02]

Y. Qi, W. Bi, Y. Wang, Yanshan Univ. (China)

$7509 \mathrm{OH} \quad$ Key-problem analysis and experimental research of stereo HMD used in augmented reality [7509-10]

W.-Q. Gao, S.-E Zhou, G.-Q. Lv, Hefei Univ. of Technology (China); H. Ming, Univ. of Science and Technology of China (China)

7509 Ol Analysis on working status of support device with 3-point used in high precision system [7509-37]

Z. Wang, Beijing Institute of Technology (China) and Henan Univ. of Technology (China);

Y. Zhao, Beijing Institute of Technology (China)

7509 OJ Development and application of wedge-shaped probes in an ultrafast measurement system [7509-65]

T. Lan, S. Chen, C. Li, G. Ni, Beijing Institute of Technology (China) 
7509 OK Passively mode-locked femtosecond fiber laser using a SESAM [7509-47]

H. P. Li, X. L. Wu, D. S. Zhao, J. K. Liao, Y. Liu, Y. Z. Liu, Univ. of Electronic Science and Technology of China (China)

7509 OL All-fiber passively mode-locked ytterbium fiber laser with a rectangular spectrum profile [7509-31]

G. Chen, C. Gu, H. Zheng, A. Wang, H. Ming, L. Xu, Univ. of Science and Technology of China (China)

7509 OM Mutual injection-locking of two double-clad fibers for coherent beam combining with corner cube [7509-32]

R. Zheng, L. Xu, Univ. of Science and Technology of China (China); Y. Liu, Wuhan Ordnance Noncommissioned Officer Academy (China); K. Gao, Univ. of Science and Technology of China (China); Y. Cheng, Wuhan Ordnance Noncommissioned Officer Academy (China); H. Ming, Univ. of Science and Technology of China (China)

7509 ON Experimental study and theoretical simulation for high gain compact $\mathrm{Er}^{3+} \mathrm{Yb}^{3+}$-codoped fiber laser [7509-35]

F. Song, Z. Cheng, Nankai Univ. (China); C. Zou, Guangdong Co., Ltd. (China); L. Luo, Y. Cai, W. Piao, C. Wei, J. Tian, Nankai Univ. (China)

\section{POSTER SESSION}

$750900 \quad$ Effect of speckle pattern on laser Doppler velocimeters by varying angle between the laser beam direction and the velocity [7509-01]

L. Lu, J. Dai, Anhui Univ. (China); H. Ming, Univ. of Science and Technology of China (China)

7509 OP Study on infrared optical switching of vanadium dioxide thin film [7509-07]

H. Wang, Univ. of Shanghai for Science and Technology (China); Y. Li, Univ. of Shanghai for Science and Technology (China) and Shanghai Key Lab. of Modern Optical Systems (China); X. Yu, Univ. of Shanghai for Science and Technology (China); H. Zhu, Univ. of Shanghai for Science and Technology (China) and Wuyi Univ. (China); Y. Huang, H. Zhang, W. Zhang, Univ. of Shanghai for Science and Technology (China)

$75090 Q \quad$ Ultra-broadband light source for optical coherence tomography by fiber matching [7509-14]

Z. Wang, L. Zhang, Tianjin Univ. (China)

7509 OR A white-and-blue mixed LED backlight for airplane display [7509-16]

H. Wu, Q. Feng, G. Lv, Key Lab. of Special Display Technology (China) and Hefei Univ. of Technology (China)

7509 OS Phase noise properties of 7 Yb-doped ten-watt level fiber amplifier array [7509-17] J. Wang, P. Zhou, Y. Ma, L. Si, National Univ. of Defense Technology (China) 
7509 OT A CMOS readout integrated circuit with automatic deselecting function for IRFPA [7509-20] S. Liu, Shanghai Institute of Technical Physics (China) and Graduate School of Chinese Academy of Sciences (China); R. Ding, Shanghai Institute of Technical Physics (China); Y. Pang, Z. Chen, Shanghai Institute of Technical Physics (China) and Graduate School of Chinese Academy of Sciences (China)

7509 OU Beam quality and power scalability of fiber laser array in a S-F cavity [7509-23] P. Zhou, X. Wang, Y. Ma, H. Ma, X. Xu, Z. Liu, National Univ. of Defense Technology (China)

7509 OV Efficiency analysis on coherent beam combination of fiber lasers using phase gratings [7509-24]

P. Zhou, X. Wang, Y. Ma, H. Ma, X. Xu, Z. Liu, National Univ. of Defense Technology (China)

7509 OW Optimal design for the two degrees-of-freedom optical switch [7509-25]

F. Zhao, Beijing Technology and Business Univ. (China); P. Wang, Beijing Institute of Technology (China); Y. Gong, L. Zhang, C. Meng, Beijing Technology and Business Univ. (China)

7509 OX 2×2 polymeric electro-optic MZI switch using multimode interference couplers [7509-29] H. P. Li, J. K. Liao, X. G. Tang, R. G. LU, Y. Z. Liu, Univ. of Electronic Science and Technology of China (China)

7509 OY All-fiber smooth supercontinuum generation in highly nonlinear dispersion-shifted fiber [7509-33]

X. Zhang, C. Gu, L. Xu, A. Wang, G. Chen, H. Zheng, R. Zheng, H. Fu, H. Ming, Univ. of Science and Technology of China (China)

7509 OZ Influence of waveguide width on transmission through metallic slit array with perpendicular waveguides [7509-34]

Y. Wang, Y. Wang, Harbin Institute of Technology (China); J. Ye, Capital Normal Univ. (China); Y. Zhang, Harbin Institute of Technology (China) and Capital Normal Univ. (China)

750910 Realization of a 10M/100Mbps CMOS monolithic optical receiver [7509-40] H. Yan, J. Li, X. Cheng, J. Lu, Y. Huang, C. Chen, Xiamen Univ. (China)

750911 Fabrication of a monolithic optical receiver for 850nm fiber transmission [7509-41] J. Li, H. Yan, X. Cheng, Y. Huang, Q. Ke, C. Chen, Xiamen Univ. (China)

750912 Electro-optic effect of dye-doped silica thin films [7509-42] W.-J. Yuan, A.-L. Hou, Changchun Univ. of Technology (China); H.-F. Liu, J. Sun, Z.-X. Yan, W.-N. Gao, D.-M. Zhang, M.-B. Yi, Jilin Univ. (China)

750913 White organic light-emitting diodes based on fluorescent dyes 7-diethylamino-3-(2-thienyl) chronmen-2-ylidene]-2,2-dicyanoviny-lamine [7509-43]

L. Li, J. S. YU, S. J. YU, Y. D. Jiang, Univ. of Electronic Science and Technology of China (China)

750914 Photoelectric characteristics of organic light-emitting device based on a small molecular fluorene derivative [7509-46]

J. Qian, J. Yu, Y. Jiang, S. Lou, Univ. of Electronic Science and Technology of China (China);

Q. Zhang, Shanghai Jiaotong Univ. (China) 
750915 Regulation of external harmonic frequency on the route to chaos [7509-50]

$X$. Chu, Beijing Institute of Technology (China) and Beijing Purkinje General Instrument Co., Ltd. (China); Y. Zhao, L. Dong, Beijing Institute of Technology (China); L. Kong, Beijing Purkinje General Instrument Co., Ltd. (China)

750916 An optimized design of a dual-core photonic crystal fiber coupler [7509-52] F. XU, D. Tao, M. Shi, C. Jiang, B. Zhang, X. Shi, B. Yu, Anhui Univ. (China)

750917 Micro-ring resonator filter based on photonic crystal fiber [7509-55] M. Shi, F. Xu, D. Tao, J. Liang, X. Shi, W. Wu, B. Yu, Anhui Univ. (China)

750918 Laser lead-fluoride nano-glassceramics for photonic applications [7509-57] V. Aseev, Saint-Petersburg State Univ. of Information Technologies, Mechanics and Optics (Russian Federation); E. Kolobkova, Saint-Petersburg State Technological Institute (Russian Federation); A. Klement'eva, K. Moskaleva, N. Nikonorov, Saint-Petersburg State Univ. of Information Technologies, Mechanics and Optics (Russian Federation)

750919 Temperature sensibility for electro-optic modulator based on LiNbO 3 crystal [7509-59] Y.-H. Wang, Beijing Institute of Technology (China) and North Univ. of China (China); P. Guo, G.-Q. Ni, K. Gao, Beijing Institute of Technology (China)

7509 1A Study on the polarization scrambling time for ultra-high-speed optical fiber communication systems [7509-63]

N. Jia, T. Li, K. Zhong, T. Gong, D. Lu, M. Chen, C. Wang, Beijing Jiaotong Univ. (China)

Author Index 
Downloaded From: https://www.spiedigitallibrary.org/conference-proceedings-of-spie on 26 Apr 2023

Terms of Use: https://www.spiedigitallibrary.org/terms-of-use 


\title{
Symposium Committees
}

\author{
General Chair
}

Songlin Zhuang, University of Shanghai for Science and Technology (China)

General Cochairs

Yuri Chugui, New Siberia Academy of Sciences (Russian Federation)

Arthur E. T. Chiou, National Yan-Ming University (Taiwan, China)

Honorary Chairs

Daheng Wang, Chinese Academy of Sciences (China)

Teruo Hiruma, Hamamatsu Photonics K.K. (Japan)

Guoguang Mu, Nankai University (China)

Bingkun Zhou, Tsinghua University (China)

Technical Program Chair

Guofan Jin, Tsinghua University (China)

Technical Program Cochairs

Yimo Zhang, Tianjin University (China)

Sien Chi, National Chiao Tung University (Taiwan, China)

Local Organizing Committee Chair

Youhua Wu, China Instrument and Control Society (China)

Local Organizing Committee Cochairs

Guoqiang Ni, Beijing Institute of Technology (China)

Daoyin Yu, Tianjin University (China)

Yulin Xi, Beijing Hamamatsu Photon Techniques Inc. (China)

Zhengji Ni, Shanghai University of Science and Technology (China)

Jinxue Wang, SPIE (United States)

General Secretary

Youhua Wu, China Instrument and Control Society (China) 
Administrative Vice General Secretary

Boyu Ding, Beijing Institute of Technology (China)

Vice General Secretaries

Hanquan Zhang, China Instrument and Control Society (China)

Yuejin Zhao, Beijing Institute of Technology (China)

Xiongwen Qin, China Instrument and Control Society (China)

Tiegen Liu, Tianjin University (China)

Qionghui Feng, Shanghai University of Science and Technology (China)

Cunlin Zhang, Capital Normal University (China)

Local Organizing Committee

Weimin Chen, Chongqing University (China)

Hongda Chen, Institute of Semiconductors, CAS (China)

Yan Zhang, Capital Normal University (China)

Shangzhong Jin, Chinese Jiliang University (China)

Boshun Hu, Modern Scientific Instruments (China)

Libo Yuan, Harbin Engineering University (China)

Tian Lan, Beijing Institute of Technology (China) 


\title{
Conference Committee
}

\author{
Conference Chairs
}

Xuping Zhang, Nanjing University (China)

Wojtek J. Bock, Université du Québec en Outaouais (Canada)

Xuejun Lu, University of Massachusetts Lowell (United States)

Hai Ming, University of Science and Technology of China (China)

Program Committee

Xiaoyi Bao, University of Ottawa (Canada)

Sien Chi, National Chiao Tung University (Taiwan, China)

Haiyong Gan, OmniVision Technologies Inc. (United States)

Yi Li, University of Shanghai for Science and Technology (China)

Edwin Y.B. Pun, City University of Hong Kong (Hong Kong China)

Ping Shum, Nanyang Technological University (Singapore)

Feng Song, Nankai University (China)

Suning Tang, Crystal Research, Inc. (United States)

Scott S. H. Yam, Queen's University (Canada)

Jianyi Yang, Zhejiang University (China)

Jianguo Zhang, London South Bank University (United Kingdom) 
Downloaded From: https://www.spiedigitallibrary.org/conference-proceedings-of-spie on 26 Apr 2023

Terms of Use: https://www.spiedigitallibrary.org/terms-of-use 


\section{Introduction}

These proceedings result from the 2009 International Conference on Optical Instrument and Technology (OIT'09), held in Shanghai, China, 19-21 October 2009. The conference was the second event following the success of OlT'08 and it was sponsored and supported by SPIE, China Instrument and Control Society (CIS), and the Chinese Optical Society (COS).

OIT'09 was a professional conference which was combined with the exhibition of The 20th Fair for Measurement Instrumentation and Automation (MICONEX).

OIT'09 focused on instrument science and related technology involved in many technical aspects such as detection; observation; information collection, transfer and storage; communication; economization on energy; environmental protection; inspection and prevention of food security, traffic safety and mine safety; measure and control for aviation and space engineering, etc.

These proceedings, a collection of eight volumes, contain the accepted oral and poster papers presented at OIT'09. It is truly a great pleasure for me that the most recent progress in optical instrumentation technology is reported in the OIT'09 proceedings. I firmly believe that the papers included in these volumes will provide reference information in up-to-date techniques of optical instrumentation technology.

The OlT'09 conference collected over 630 papers from different countries or regions of the world. Over 400 authors came from more than 14 countries, including Canada, Iran, Japan, Russia, Singapore, USA, Sweden, Switzerland, Pakistan, the Netherlands, Republic of Korea, Slovenia, Germany and China. Published in these eight volumes of the Proceedings of SPIE are close to 455 papers. The technical fields of the presented papers at the conference cover a lot of current advanced technologies. The cutting-edge technologies and applications of optical instruments are discussed. Quite a few invited papers describe exciting achievements in the fields of optical instrument technology. It is evident that the OIT'09 conference has provided an excellent platform for participants and colleagues in research and development to share the technical progress and to develop new partnerships or broaden new markets.

SPIE has given great support to organize this international conference by collaborating with us in the whole organizing process from paper collection to the proceedings publication. COS has provided enough support and assistance.

Finally, on behalf of CIS and conference general chairs, I would like to heartily thank our supporters and committee members for all they have done for this conference. Thanks also go to all authors for their contributions; to all of the 
participants and friends for their interest, especially those who have traveled great distances and taken time from their busy schedules to attend the conference. Thanks also go to the staff of COS for their support. I am also grateful to the SPIE staff for their support and collaboration in publishing these eight volumes.

Songlin Zhuang Chairman, China Instrument and Control Society (CIS) 